\title{
ALFONSO REYES EN SUR AMÉRICA DIPLOMACIA Y CAMPO INTELECTUAL EN AMÉRICA LATINA, 1927-1939*
}

\author{
Aimer Granados
}

\begin{abstract}
Resumen
Este trabajo analiza la evolución del campo intelectual latinoamericano entre 1927 y 1939, a partir del accionar diplomático e intelectual del mexicano Alfonso Reyes, uno de los más importantes intelectuales hispanoamericanos del siglo XX. La metodología que se utiliza tiene en cuenta algunos de los aspectos señalados por Pierre Bourdieu y otros investigadores como centrales en la conformación de un campo intelectual. El trabajo parte de la tesis según la cual en América Latina se puede hablar de un campo intelectual a partir de la transición del siglo XIX al XX, pero especialmente se estudian y evalúan algunas situaciones y circunstancias de carácter intelectual y diplomático que permitieron a Reyes dinamizar la cultura continental durante el período en estudio.
\end{abstract}

Palabras clave: Alfonso Reyes, campo intelectual, historia intelectual, Latinoamérica, historiografía, intelectual, escritor, diplomacia, revistas, libros, México, Argentina, Brasil.

\section{Abstract}

This document analyzes the evolution of the Latin American intellectual field between 1927 and 1939, from the diplomatic and intellectual actions of the Mexican Alfonso Reyes, one of the most important Latin American intellectuals of the 20th century. The methodology used takes into account some of the aspects that Pierre Bourdieu and other researchers consider as central in the formation of an intellectual field. The research departs from the thesis according to which in Latin America you can only talk about intellectual field from the 19th to the $20^{\text {th }}$ century transition, but it is especially studied and evaluated some situations and circumstances of intellectual and diplomatic character that allowed Reyes to boost mainland culture during the period under review.

\footnotetext{
*Artículo tipo 3: de revisión según clasificación de Colciencias.

** Doctor en Historia del Colegio de México, coordinador Cuerpo Académico Historia Intelectual del Departamento de Humanidades de la Universidad Autónoma Metropolitana - Cuajimalpa. Email: aimer@correo.xoc.uam.mx.
} 
Key words: Alfonso Reyes, intellectual field, intellectual history, Latin America, historiography, intellectual, writer, diplomacy, magazines, books, Mexico, Argentina, Brazil.

\section{Introducción}

La perspectiva de análisis que se adopta en este estudio indaga por la frontera de funciones entre la diplomacia y el trabajo intelectual que muchos hombres de letras han realizado. Desde la historia intelectual se puede formular la existencia de un modelo de intelectual que, por su misma formación y trayectoria en letras, periodismo, historia o, siendo profesional en alguna de las área de las ciencias sociales como académico o investigador, se vinculó de manera interactiva con el mundo de la diplomacia, la política, la cultura y de las relaciones internacionales. En México, este encuentro entre los intelectuales, la diplomacia, la política y la cultura en sentido amplio, ha sido notable. No solamente porque ha estado presente desde los inicios del período republicano, sino también por la calidad de los intelectuales que han asumido labores diplomáticas y, por los resultados que sus acciones han representado para la consolidación del país en el ámbito internacional.

El objetivo central de este trabajo es analizar una de estas múltiples situaciones en que un intelectual y hombre de letras, en este caso Alfonso Reyes, logró involucrar y vincular su devenir como funcionario del servicio exterior mexicano, con las actividades propias de un intelectual y hombre de letras, de tal suerte que uno y otro oficio fueron complementarios. La hipótesis que a continuación argumento plantea que dicho cruce de actividades, de alguna manera incidió en la transformación del campo intelectual en América Latina durante el periodo comprendido entre 1927 y 1938, cuando Reyes fue embajador mexicano ante las repúblicas de Argentina y Brasil. Ciertas características del intelectual mexicano permiten señalar que en su caso y en relación con su entorno intelectual se configuraron algunos de los elementos claves en la reestructuración de un campo intelectual: Desde muy temprano en el siglo XX y en su trayectoria Reyes se asume como un escritor profesional ${ }^{1}$. Igualmente en este personaje encontramos el prototipo del nuevo intelectual del siglo XX (Charle, 2009, Zermeño, 2003 y 2010). También, en torno a este personaje interactúa una "comunidad de escritores" latinoamericanos y europeos que articulan proyectos de cooperación e intercambio universitario y bibliográfico. Reyes, al menos en la geografía iberoamericana, es central en el mundo de la edición, circulación y mercado del libro, así como creador y miembro de comités editoriales y de revistas culturales y literarias. Además, nuestro personaje participa, desde una perspectiva

\footnotetext{
${ }^{1}$ Alfonso Reyes nació en la norteña ciudad de Monterrey, México, en 1889. Cuando tenía 16 años aparecieron publicados sus primeros poemas. En 1908 comenzó a escribir ensayos que posteriormente fueron incluidos en sus libros. En 1911, en París, se publicó Cuestiones Estéticas, su primer libro, en ese entonces tenía 22 años. A ello hay que agregar que para ese momento Reyes ya tenía un cúmulo de experiencias en el ámbito de la cultura, adquiridas en buena parte de la mano de su tutor Pedro Henríquez Ureña. Para conocer la etapa formativa de Reyes en la ciudad de México es muy útil Quintanilla (2008).
} 
ideológica, en asuntos tan trascendentales como los avatares de una supuesta "literatura revolucionaria y nacionalista" pregonada por algunos de los "caudillos culturales" (Krauze, 1996) de la Revolución Mexicana que, en opinión de Reyes debía ser universalista y cosmopolita, (Granados, 2008). También hay que señalar que asumió labores de cabildeo y defensa del proyecto revolucionario mexicano, como proyectar una cierta estabilidad del Estado de la Revolución, o afrontar y explicar ante los gobiernos europeos y latinoamericanos la situación de la Guerra Cristera, o intentar vender el petróleo nacionalizado por Lázaro Cárdenas (Yankelevich, 1997, p. 341 y ss.). Aunque habrá que señalar que no del todo podemos hablar de un Reyes en calidad de un "intelectual orgánico" (Gramsci, 2009, pp. 9-21) del Estado revolucionario, pues también fue crítico de él. Por otra parte debe considerarse el tipo de labor cultural que realizaba paralelamente 0 , como parte de sus labores como diplomático (empresario cultural, escritor en torno al cual posiblemente se pueda hablar de una red de intelectuales, editor, impulsor de proyectos culturales de integración latinoamericana, polemista y ensayista, entre otras actividades), (Granados, en prensa). Cabe señalar que este trabajo hace parte de una investigación más amplia que, sobre la red intelectual de Alfonso Reyes en Iberoamérica, el autor de este trabajo viene realizando.

La tradición del intelectual diplomático en México ha sido una constante a lo largo de sus dos siglos de vida independiente. Lucas Alamán, José María Lafragua, Manuel Payno, José Tomás de Cuéllar, Vicente Riva Palacio, Ignacio Manuel Altamirano entre otros muchos, son ejemplo, durante el siglo XIX, de la incorporación del mundo de las letras a la diplomacia, la política y las relaciones internacionales. En el siglo XX la lista es igualmente representativa, menciono algunos nombres, Amado Nervo, Justo Sierra, Francisco A. de Icaza, José Vasconcelos, Jaime Torres Bodet, José Gorostiza, Antonio Castro Leal, Antonio Gómez Robledo, Fernando Benítez, Rafael Bernal, José Luis Martínez, Octavio Paz, Carlos Fuentes, Sergio Pitol, Fernando del Paso y, por supuesto, nuestro personaje en estudio, Alfonso Reyes.

Técnicamente las actividades de Alfonso Reyes en el servicio exterior mexicano iniciaron en agosto de 1913 cuando fue nombrado segundo secretario de la legación mexicana en Francia. Las actividades de carácter diplomático del escritor mexicano, interrumpidas muy frecuentemente, especialmente a partir de 1939 año en el que regresa a México definitivamente, finalizan cuando en noviembre-diciembre de 1946, siendo presidente de El Colegio de México, presidió la delegación mexicana ante la I Asamblea Internacional de la UNESCO, con categoría de embajador. Previamente, en julio de 1938 el presidente Lázaro Cárdenas lo había nombrado en misión diplomática especial en Brasil, con el fin de vender el petróleo recién nacionalizado. En suma, entre 1913 y 1946 Reyes desempeñó diferentes cargos en el servicio exterior mexicano: segundo y primer secretario de legación en Francia y España, encargado de negocios, ministro plenipotenciario en diferentes misiones diplomáticas y, entre 1927 y 1930 como 
embajador en Argentina, lo volvería a ser en este país entre 1936 y 1937; entre 1930 y 1936 como embajador en Brasil (Garciadiego, 2009 \& Díaz, 2001)².

\section{El intelectual diplomático: el caso de Alfonso Reyes en la historiografía mexicana}

En la historiografía mexicana ha habido cierta preocupación por el estudio del hombre de letras, muy frecuentemente desdoblado en intelectual que, ha incursionado en el mundo de la diplomacia y de las relaciones internacionales. Un ejemplo de ello son los tres tomos que bajo el auspicio de la Secretaría de Relaciones Exteriores de México se publicaron en la transición del siglo XX al XXI. En este trabajo un conjunto de investigadores se dieron a la tarea de realizar estudios de caso sobre hombres de letras que incursionaron en la diplomacia, (Secretaría, 1988, 2000 y 2002) ${ }^{3}$.

Dado el peso específico de la trayectoria de Reyes como literato, las investigaciones que sobre él se han realizado, especialmente tienen un abordaje a partir de su obra como humanista, escritor y crítico literario. No obstante, a fines de la década de 1970 apareció un trabajo que tal vez haya sido el primero que, de una manera sistemática y no solamente referencial, inició el estudio del Reyes diplomático (Patout, 1990) ${ }^{4}$. Este trabajo constituye una visión general sobre la trayectoria diplomática de Reyes que, analiza las diferentes misiones diplomáticas y contextos culturales de Reyes en Francia, España, Argentina y Brasil, enfatizando a lo largo de su análisis, la especial atención que Reyes puso a la relación entre la diplomacia, la política interna y externa de México, con las letras y, en general con el mundo de la cultura y sus actores. Esta línea de investigación también ha sido abordada por (Garciadiego, 1998, 2000 y 2006). En tanto que (Ellison, 2000 y Aponte, 1972), han centrado sus estudios en el desempeño diplomático y vivencias intelectuales de Reyes en Brasil y España, respectivamente. Por otra parte, (Perea, 1997) ha realizado una compilación documental y de textos de Reyes en España y, (Enríquez Perea, 2009) lo ha hecho para la estancia del mexicano en Brasil.

Dentro de esta trayectoria de estudios sobre el Reyes diplomático hay que hacer mención especial al prólogo (Díaz Arciniega, 2001) a la compilación Alfonso Reyes. Misión Diplomática ${ }^{5}$. En este texto Díaz Arciniega enfatiza en el perfil de

\footnotetext{
${ }^{2}$ Ambos estudios contienen cronologías muy útiles para darse a una idea general sobre la vida y trayectoria de Reyes. También es muy útil el expediente personal de Reyes en el Archivo Histórico Diplomático de la Secretaría de Relaciones Exteriores de México.

${ }^{3}$ Los volúmenes I y II de esta serie están dedicados al hombre de letras del siglo XIX, en tanto que el volumen III aborda estudios de caso del diplomático intelectual del siglo XX,

${ }^{4}$ Este libro data de 1978 cuando en edición francesa salió bajo el titulo Alfonso Reyes et la France.

${ }^{5}$ En dos volúmenes Díaz Arciniega recoge, a partir de diferentes fuentes históricas, pero especialmente del expediente de Reyes conservado en el Archivo Histórico Diplomático "Genero Estrada", de la Secretaría de Relaciones Exteriores del gobierno mexicano, los textos de carácter diplomático más importantes producidos por Reyes a su paso por España, Francia, Argentina y Brasil, en calidad de representante oficial de México ante estos países. Dicho sea de paso, esta compilación es muy importante para una investigación que tenga
} 
Reyes como diplomático. En este estudio su autor logra evidenciar los "pormenores de una condición", la del diplomático, según la entendía Reyes. Es importante destacar en este trabajo, como en los demás que han analizado la trayectoria de Reyes como diplomático, la fuerte vinculación que él realizó entre las tareas propias de la diplomacia (llevar la representación del país ante otro gobierno, velar por sus intereses económicos y políticos, resolver problemas puntuales en relación con el país que se representa, lograr establecer convenios de toda naturaleza, hacer presencia y lograr que el gobierno al cual se representa tenga prestancia en las relaciones internacionales, entre otros aspectos), y el mundo de la cultura, de la literatura, de las artes, de los intelectuales y de los lazos de la cultura. Una tercera línea que resalta en este estudio es detallar las más importantes acciones diplomáticas emprendidas por Reyes, tanto en Europa como en Sur América.

Por su parte, (Castañón, 2008), entre otros aspectos pondera muy favorable y positivamente los documentos recogidos por Víctor Díaz Arciniega en Alfonso Reyes. Misión diplomática. Pero igualmente destaca cómo esta compilación documental es invaluable para la comprensión de Alfonso Reyes como escritor. Igualmente Castañón destaca el contexto internacional en el que le tocó a Reyes desempeñarse como diplomático, justamente el período de entreguerras, caracterizado por inestabilidad económica y política, no sólo en México, sino también a nivel mundial.

Finalmente, dentro de esta revisión historiográfica sobre los estudios que han analizado la trayectoria de Alfonso Reyes como diplomático, está el trabajo de (Myers, 2010). Lo primero que resalta en el análisis de este autor es que ubica a Reyes como parte de una familia de pensadores europeos y americanos que durante las primeras décadas del siglo pasado se apegaron a los valores de "cierto humanismo liberal" del cual, entre otros, también hicieron parte Paul Valéry, Julien Benda, Thomas Mann, Américo Castro y Benedetto Crocce. Además, el análisis de Meyer sobre el Reyes intelectual y diplomático, parte de la tesis según la cual tres de los oficios más centrales en su trayectoria, el periodismo político y cultural, la disciplina académica de la filología y la diplomacia, plasmaron el oficio de escritor. Como los anteriores trabajos ya comentados, Myers también destaca en su análisis cómo nuestro personaje entrecruzó su trayectoria como intelectual con la del ejercicio de la diplomacia.

\footnotetext{
por objeto estudiar la trayectoria de Reyes como diplomático. De esta compilación hay antecedentes en algunos de los tomos publicados por el mismo Reyes bajo el título Archivo de Alfonso Reyes. Como ya ha sido referenciado, (Castañón, 2008, p. 200), Alfonso Reyes. Misión Diplomática, viene a sumarse, como un cuerpo documental más, a los 26 tomos de su obra completa, al conjunto de epistolarios del autor, parcialmente publicados y los que no, que reposan en la "Capilla Alfonsina" de la Ciudad de México y a su Diario que, recientemente ha sido retomado para ser publicado y del cual ya han salido a la luz pública dos tomos correspondientes a los periodos 1911-1927 y 1927-1930.
} 


\section{El intelectual, la diplomacia y el campo intelectual}

Frente a estos trabajos brevemente reseñados en el apartado anterior, lo que a continuación planteo es complementario, pero a la vez pretende ser un aporte más al estudio de la figura del diplomático intelectual. Ello con el fin de señalar que, en el caso de Alfonso Reyes, su doble faceta profesional, entre el intelectual y el diplomático, ejercida de manera simultánea y cruzada $^{6}$, incidió en la transformación y fortalecimiento del campo intelectual latinoamericano durante el periodo comprendido entre 1927 y 1939 . Temporalidad ésta que corresponde a su desempeño como embajador de México ante Argentina y Brasil. Desde su posición como diplomático y como representante del gobierno de varios de los presidentes del Estado de la Revolución, incluyendo a los muy importantes Plutarco Elías Calles, Álvaro Obregón y Lázaro Cárdenas, Reyes empleó la diplomacia como una mecanismo a través del cual empujó la conformación de una red de escritores con carácter trasnacional latinoamericano y trasatlántico vis a vis América - España-Francia. Por demás está señalar que las misiones diplomáticas de Alfonso Reyes en Sur América, aunque también las de Europa, de alguna manera deben enmarcarse en un esfuerzo de los gobiernos mexicanos por proyectar la revolución mexicana hacia el contexto latinoamericano (Yankelevich, 1994, 1997 y 2003) o, europeo, según correspondiera.

En América Latina, al igual que en muchos otros puntos de la geografía internacional, durante la transición del siglo XIX al XX progresivamente el campo intelectual se fue transformando (Zermeño, 2003). En tal periodización hay más o menos acuerdo para los casos particulares de Argentina (Altamirano y Sarlo, 1997 y, Losada, 2009, pp. 207-216) y de México (Quintanilla, 2008 y Zermeño, 2010). De acuerdo con (Zermeño, 2003, p. 780), aún el "antiguo régimen preindustrial" hispanoamericano de fines del siglo XIX y principios del XX, "generó las condiciones necesarias para la aparición y desarrollo de un nuevo tipo de "sabio" enmarcado por la creación de un espacio comunicativo propio. El ocaso relativo de la filosofía positivista coincidió con la declinación de las "funciones públicas" de grupo establecidos en el gobierno y la emergencia de una nueva esfera de opinión pública enfocada ha convertirse en la conciencia moral de la sociedad". El nuevo tipo de "sabio" al que alude Zermeño es propiamente el intelectual, un fenómeno socio-cultural del siglo XX (Charle, 2009 \& Winock, 2010). El "espacio comunicativo propio" del intelectual del que habla Zermeño que, remite a la autonomía del campo (Bourdieu, 1992, p. 79 y ss.), en el medio latinoamericano implicó la agregación de una serie de factores sin los cuales la renovación del campo intelectual hubiera sido imposible.

Por ejemplo, una reflexión acerca de la actividad literaria, de tal manera que el escritor progresivamente se convierte en un profesional. Reyes, como ya se afirmó, hace parte de un grupo de escritores latinoamericanos (José Ingenieros en

\footnotetext{
${ }^{6}$ Esta circunstancia de encontrarse entre dos oficios no estuvo exenta de quejas por parte de Reyes, al no poder dedicarse única y exclusivamente a las tareas de escritor. Hay constancia de esta lamento en su Diario, (Reyes, 1969). También véase su epistolario con Pedro Henríquez Ureña, (Reyes, 1986, vol. I).
} 
Argentina, Baldomero Sanín Cano en Colombia, los hermanos García Calderón en Perú, José Vasconcelos en México, Pedro Enríquez Ureña en Santo Domingo, etc.) que, muy temprano en el siglo XX se piensan como escritores profesionales. Esto es, viven de su oficio, a la vez que son sujeto de reconocimiento social por asumirse como escritores, programan la escritura de sus libros e implementan hábitos de trabajo circunscritos al oficio escritural. En este sentido vale la pena citar una carta de Reyes escrita en 1926, "Carta a dos amigos", dirigida a Enrique Diéz Canedo y Genaro Estrada, en la que les confiaba el "cuidado de su obra" y les daba "indicaciones respecto a la organización y grado de atención que deberían recibir sus papeles". No obstante, ante el fallecimiento de estos "albaceas literarios", Reyes inició en 1955 la publicación de sus Obras Completas y, en la misma fecha dio inicio a su Historia documental de mis libros (Martínez, 1989, p. 496). ${ }^{7}$

Otro factor de singular importancia fue la imposición de instancias de consagración y cooptación, muchas veces determinadas por el creciente mercado del libro, o por las instituciones culturales del Estado, o por espacios culturales abiertos por iniciativa de los intelectuales. El creciente mercado del libro es fundamental para la recomposición de un campo intelectual-cultural, en tanto que va unido a un público cuya relación con los textos y los escritores más o menos está mediada por la venta del libro o la revista. A ello se debe agregar la renovación de la Universidad, particularmente la que resurge de la reforma universitaria de Córdoba de 1918. En el caso de México es de singular importancia la creación en 1910 de la Universidad Nacional de México. Uno de los antecedentes inmediatos de la Universidad fue la Escuela Nacional Preparatoria de donde egresó Reyes en 1907 y en la que presidió la Sociedad de Alumnos. Otro importante precedente de la Universidad fue la Escuela Nacional de Jurisprudencia en donde Reyes se tituló como abogado en 1913. También es importante reseñar que en agosto de 1912 fue nombrado Secretario de la Escuela Nacional de Altos Estudios, creada simultáneamente con la Universidad Nacional de México en 1910, de la mano de Justo Sierra. En suma, en los albores del siglo XX México vivió una interesante renovación de los estudios superiores que definitivamente fue muy importante para la renovación del campo cultural e intelectual.

También hay que considerar a las revistas y a sus comités editoriales. Reyes, por ejemplo, escribió e hizo parte de la mesa de redacción de Savia Moderna; estando en Brasil crea Monterrey. Correo Literario de Alfonso Reyes y en su primera estancia en Argentina fundó la revista Cuadernos del Plata, además fue miembro del comité editorial de la famosa e importante revista Sur, de Victoria Ocampo. Otro de los aspectos que debe ser considerado en coadyuvar a la generación de condiciones que permitieran la transformación del campo intelectual

\footnotetext{
${ }^{7}$ Editadas por el Fondo de Cultura Económica entre 1955 y 1993, hasta la fecha las $O C$ de Reyes lleva XXVI tomos. En cuanto a la Historia documental de mis libros, hay que señalar que solo cubre desde los inicios literarios del autor y su primer libro Cuestiones estéticas (1911), hasta el año de 1925. Historia documenta de mis libros, originalmente fue publicada por entregas en varias revistas culturales de la México, entre 1955 y 1959.
} 
son las organizaciones de escritores y sus manifiestos. En cuanto a lo primero como el famoso PEN Club Internacional (poetas, ensayistas y novelistas), la asociación de escritores creada en Londres en 1921, cuyo XIV Congreso Internacional se realizó en Buenos Aires en 1936, al cual asiste el intelectual mexicano. Desde muy temprano el PEN Club Internacional contó con capítulos en Ciudad de México y en Buenos Aires. Por otra parte, en el contexto mexicano se puede mencionar la creación en 1933 de la Liga de Escritores y Artistas Revolucionarios (LEAR) que, se autodesignó como la sección mexicana de la Unión Internacional de Escritores y Artistas Revolucionarios, fundada en 1930 en Charkov, antigua URSS. Aunque hay que señalar que Reyes no hizo parte de la LEAR. Sólo la menciono en la idea de apoyar la argumentación según la cual durante el periodo en estudio los intelectuales hacen parte de una nueva esfera de opinión pública.

Los manifiestos de los intelectuales constituyen otro factor que abunda en la idea de la creación de nuevas condiciones para la emergencia del intelectual de nuevo cuño, el intelectual del siglo XX. A partir del famoso caso Dreyfus (18941906), (Charle, 2009, p.123 y ss.) ha encontrado un quiebre en la representación que diferentes sectores sociales e institucionales habían tenido sobre el intelectual. Entre otros aspectos esta nueva representación involucra el compromiso político de los intelectuales que actúa directamente sobre la esfera de opinión pública. Es así que en el contexto del caso Dreyfus, Emil Zola y otros hombres de letras de la época, lanzan su famosa protesta y se manifiestan a favor del capitán Alfred Dreyfus en la famosa carta abierta al presidente de Francia M. Félix Faure y publicado por el diario L'Aurore el 13 de enero de 1898 en su primera plana, bajo el titulo J'Accuse. En la historia de la literatura mexicana del siglo XX es muy famosa una "Protesta literaria" que fue distribuida mano a mano y publicada en El Diario de México, el domingo 7 de abril de 1907. La protesta estaba dirigida contra la intención de revivir la Revista Azul. Lo interesante de este manifiesto-protesta, el cual fue firmado por parte de la juventud literaria de la época, Alfonso Reyes, Pedro Henríquez Ureña, Luis Castillo Ledón, Ricardo Gómez Robelo y Alfonso Cravioto entre muchos otros, es el tono de denuncia, de manifiesto y, como lo ha dicho Gabriel Zaid: "tomar la calle, salir a la vida pública y decir: aquí estamos, miren la fuerza que tenemos, el talento que tenemos, la razón que tenemos (citado por Quintanilla, 2008, p. 54). Efectivamente, hay en este manifiesto una intención de incidir sobre la esfera de opinión pública. El hecho de que hubiera circulado en la prensa, que fuera firmado por lo más excelso de la juventud literaria de la época y que generara debate entre diferentes periódicos, son señales de la recomposición del campo literario mexicano.

En este panorama de mostrar los factores que prefiguraron la renovación del campo intelectual latinoamericano durante el periodo en estudio, también las conferencias $y$, muy frecuentemente unidas a ellas, los ateneos, son de importancia. El Ateneo de la Juventud Mexicana, más adelante conocido como El Ateneo de México, fundado en 1909 con el propósito de trabajar por la cultura y el arte, organizando para ello reuniones, conferencias y debates públicos 
(Hernández Luna, 1984) dan prueba de su relevancia. ${ }^{8}$ Como se sabe, entre los fundadores de El Ateneo de México estuvo Alfonso Reyes. Los ateneos tienen mucho "sabor" decimonónico, no obstante en función del análisis de la reconformación de un campo intelectual, los ateneos hispanoamericanos de principios del siglo XX y, en particular el de México, rompen con la tradición del ateneo del siglo XIX en la medida en que se abren al público, son espacios de discusión y debate y a ellos asisten intelectuales que rompen con la figura del "gentleman escritor" para dar paso a un escritor profesional que, moviliza a la opinión pública y genera debate. (Altamirano y Sarlo, 1997, p. 168-169). A esta serie de factores hay que agregar una progresiva especialización de saberes en las humanidades y en las ciencias sociales. En esto evidentemente la Universidad pública contó mucho, pero también el establecimiento de cátedras como la que en 1912 fundó Reyes: la cátedra de Historia de la Lengua y la Literatura Española. Por la misma época Ricardo Rojas funda la cátedra de Literatura Argentina. Este tipo de cátedras evidencian un esfuerzo por estructurar campos de saberes especializados, muy importantes para el desempeño intelectual. Pero también son creadas con un carácter nacionalista y de identidad nacional, (Altamirano, 1997).

Aunque la hipótesis de este trabajo plantea la conexión existente entre las labores diplomáticas e intelectuales de Reyes con miras a dinamizar el campo intelectual latinoamericano entre 1927 y 1939, es evidente que tanto sus inicios académicos en México de la mano de su tutor Pedro Henríquez Ureña, así como el desempeño en la vida cultural mexicana hasta agosto de 1913 cuando sale para Europa, son fundamentales para entender a Reyes como un protagonista de primer orden en el campo intelectual hispanoamericano de las primeras décadas del siglo XX. La estancia de Reyes en Francia en 1913 como segundo secretario de la legación mexicana y, luego en el mismo país en 1925 como ministro plenipotenciario, pero también sus misiones en España, especialmente como primer y segundo secretario de la legación mexicana en 1921, también son importantes en la medida que, como se muestra más adelante, en tales desempeños para el servicio exterior mexicano Reyes estableció contacto con instituciones culturales y educativas, así como con diferentes intelectuales. En este sentido también es importante resaltar, como lo han subrayado los autores ya reseñados, la experiencia profesional de Reyes como escritor, periodista cultural y político, editor y filólogo, adquirida en sus alternadas estancias en París y en Madrid, entre 1913 y 1927, último año éste en que llega a la Argentina ya en calidad de embajador.

A continuación menciono algunos hechos importantes relacionados con la vivencia de Reyes en los círculos de la intelectualidad parisina y madrileña, así como en la bonaerense y de Rio de Janeiro, en la idea de ir ponderando una trama de contactos directos de Reyes con importantes escritores e intelectuales

\footnotetext{
${ }^{8}$ Este autor compiló, prologó y anotó las famosas "Conferencias del Ateneo de la Juventud" realizadas en el Salón de Actos de la Escuela Nacional de Jurisprudencia (Universidad de México), entre agosto y septiembre de 1910. En ellas participaron, además de Reyes, Antonio Caso, Pedro Henríquez Ureña, Carlos Gonzalo Peña, José Escofet y José Vasconcelos. La conferencia de Reyes se tituló "Los poemas rústicos de Manuel José Othón".
} 
en ambos lados del Atlántico. Para detalles de este tejido de relaciones y amistades forjadas por Reyes véase (Patout, 1990, Garciadiego, 1988, 2006 y 2000, Aponte, 1972 y Ellison, 2000). En su primera estancia en París a partir de agosto de 1913 y hasta octubre del año siguiente, en calidad de segundo secretario de la legación mexicana en ese país, Reyes logró incursionar en el ámbito de la cultura, para lo cual se relacionó con los jóvenes intelectuales latinoamericanos residentes en París, como los hermanos García Calderón, así como con importantes intelectuales franceses, como los hispanistas Ernest Martinenche, profesor de español en La Sorbona, y con Raymond FoulcheDelbosc, autoridad en Góngora, como más tarde también lo sería Reyes. Así mismo escribió textos literarios y ensayos para algunas revistas europeas y americanas editadas en el Viejo Continente. En el segundo período de Reyes en Francia, después de un semestre de arduo trabajo, luego regresó a "su equilibrio profesional y vocacional: "es prudente en la diplomacia y activo en la literatura"; tanto que la embajada mexicana en París se convirtió en un centro de cultura: "En el patio de su casa - entre veras y bromas llamado "Jardín Academus" - reúne periódicamente a los mejores hombres de todas las artes" que, como decía Reyes, "conviene poner en contacto unos con otros". Como en su primera estancia en París, entre los personajes invitados y relacionados habían hispanoamericanos, franceses, españoles y también mexicanos." (Díaz Arciniega, 2001, p. 30).

En agosto de 1914 Reyes fue cesado por el gobierno entrante de Venustiano Carranza, junto con todo el servicio exterior mexicano que había nombrado el golpista Victoriano Huerta. Ello, sumado a las circunstancias de la Gran Guerra, hizo que, en calidad de exiliado y sin empleo, nuestro personaje se trasladará a España. A grandes rasgos el período madrileño de Reyes tuvo etapas de muchas dificultades de tipo económico, especialmente en el inicio. Pero después de la segunda mitad de 1916, una vez su situación económica quedó estable, aunque no boyante, Reyes pudo hacerse a una red de amigos de prestancia intelectual y desarrollar actividades culturales y de escritura. En fin, en Madrid, Reyes prontamente trabajó como periodista y como editor de Lope de Vega, Quevedo y Gracián. Pero, todavía más importante aún, el joven Reyes entró en contacto y trabajó con la sección de filología del Centro de Estudios Históricos (CEH), dirigida por Ramón Menéndez Pidal, en donde entabló amistad con Antonio Solalinde, Federico de Onís y Américo Castro. Estos contactos, aquí y allá con parte de la inteligencia española, francesa y latinoamericana residente en París y Madrid, así como con las instituciones académicas y culturales, revistas y editoriales impulsadas por estos intelectuales, serán importantes pues le permitieron a Reyes, ya como embajador en Sur América a partir de 1927 cuando llega por primera vez a la Argentina, mantener contactos al otro lado del Atlántico, forjar una amplia red de intelectuales inmiscuidos en proyectos culturales y académicos impulsados por el mismo Reyes. Aquí habrá que subrayar que tales contactos, tanto en Francia como en España, no eran poca cosa pues París y Francia, al menos durante las primeras décadas del siglo XX, constituyeron referentes espaciales, culturales e intelectuales para la inteligencia Latinoamérica. (Patout, 1990 \& Ayllón, 2009). 
A su arribo a la Argentina, a la edad de 38 años, Reyes llegó como una celebridad, como un "escritor reconocido y un hombre que tiene lectores, amigos y amigas por todas partes". "Es el hijo del ilustre general Bernardo Reyes, el patricio ilustrado que no puede pasar inadvertido ni en el orden de la vida literaria y social, ni en el de la civil y política." (Castañón, 2010, p. XVI). En su primera estancia en Argentina fundó la revista Cuadernos del Plata y entró en contacto con Jorge Luís Borges, Victoria Ocampo y su importante revista Sur en la cual colabora. También se relacionó con Juana de Ibarbourou, la importante poetiza uruguaya, entre otras personalidades. En 1936 el famoso PEN CLUB (Poetas, Ensayistas y Novelistas) organizó en Buenos Aires un congreso. Allí Reyes se reencontró con Pedro Henríquez Ureña, Enrique Anderson Imbert, escritor, ensayista y profesor universitario argentino, con el poeta italiano Giussepe Ungaretti, y con Jules Romains entre muchos otros escritores e intelectuales. También su etapa brasileña le permitió agrandar sus contactos intelectuales y artísticos con figuras de la talla de Cecilia Meireles, considerada como la gran poetisa de la lengua portuguesa; con Manuel Bandeira otro gran poeta, además de crítico y traductor. En agosto de 1934, en Río de Janeiro la Academia Brasileña de Letras ofreció un homenaje al mexicano. En este acto, entre otros, llevó la palabra Rodrigo Octavio de Menezes Langaard, importante abogado, profesor, cuentista y poeta.

Este breve recorrido por algunos de los hitos y momentos más importantes de la vida literaria y académica de Reyes estando en París, Madrid, Buenos Aires y Río de Janeiro, permiten mostrar cómo a lo largo de más o menos dos décadas Reyes logró forjar y establecer una red intelectual que, a la vez fue muy importante en términos de un fuerte impulso al campo cultural e intelectual latinoamericano. En las labores y objetivos de la diplomacia, el amplio mundo de la cultura, de los lazos de la cultura entre países, de contactos con intelectuales, de proyectos culturales, se alterna con los ámbitos de la economía, la política, los negocios, la firma de tratados y la resolución de conflictos de carácter internacional, entre otros aspectos. No obstante, al menos por la época en estudio, en este amplio campo de funciones de un diplomático, la cultura aparecía en segundo lugar o, como subsidiaria. Sin embargo en el caso de estudio que nos ocupa me aventuro a plantear que Alfonso Reyes no jerarquizó objetivos. Esto tiene que ver con el perfil de un hombre que ante todo era un humanista y que concibió las labores del ejercicio de la diplomacia como un medio para resolver problemas de toda índole entre las naciones y los hombres, pero también como una herramienta para el acercamiento no sólo comercial y político entre los países y sus ciudadanos, sino también para tender puentes culturales entre unos y otros. Reyes entonces integró a sus múltiples actividades diplomáticas el mundo de la cultura en sentido amplio (conferencias, arte, encuentros académicos, proyectos de intercambio universitario y bibliográfico). Desde la perspectiva de los temas y proyectos que vincularon a los hombres que, de alguna manera orbitaban en torno a Reyes o, viceversa, destacan la literatura, la crítica literaria, la investigación literaria, la ensayística en torno a Latinoamérica, la formación de un catálogo bibliográfico, el intercambio de libros y los lazos de la cultura con el fin de romper el aislamiento cultural, literario y bibliográfico existente en América Latina durante la primera mitad del siglo XX. Es aquí en donde planteo que, en el caso de Alfonso Reyes la figura del intelectual 
diplomático permitió la renovación de un campo cultural e intelectual. En tal renovación confluyeron, evidentemente no sólo el esfuerzo de un intelectualembajador comprometido con la cultura, sino también unas circunstancias que, como la creciente profesionalización del oficio del escritor, del académico y del investigador, permitieron una autonomía del campo cultural latinoamericano. En esta autonomía también hay que considerar otros factores, por ejemplo, el creciente aparecimiento de revistas que nuclearon a diferentes intelectuales.

\section{Monterrey. Correo literario de Alfonso Reyes}

Justamente y, en relación a las revistas, hay que señalar que uno de los hitos más importantes en la trayectoria intelectual de Reyes en Sur América, cuando era representante diplomático de México, fue la publicación de Monterrey. Correo Literario de Alfonso Reyes ${ }^{9}$. Concebido como "carta circular a los amigos", (Reyes, 1969, pp. 302-303), Monterrey fue un impreso que contribuyó al campo cultural e intelectual latinoamericano durante buena parte de la década de los 1930. En términos generales se puede afirmar que el mundo de los impresos ha corrido paralelo al surgimiento, evolución y transformación del intelectual. Particularmente las revistas han sido punto de encuentro de intelectuales, han encauzado proyectos culturales, político-ideológicos y también han sido plataforma y espacio para la constitución de redes de intelectuales (Granados, Introducción, en prensa). El Correo Literario del intelectual mexicano cumplió con algunas de estas funciones. Así mismo, este periódico literario le permitió a Reyes construirse un espacio que le dejó cierto retiro parcial del mundo de la diplomacia y de la política. Tal recogimiento le dio la oportunidad de encontrar una ventana hacia la renovación del campo cultural e intelectual latinoamericano. Particularmente el campo literario tuvo en Monterrey espacio para la crítica literaria, para el lanzamiento de proyectos bibliotecarios, para el debate literario, para la circulación de novedades bibliográficas y para el contacto con intelectuales dispersos en la amplia geografía latinoamericana.

En el editorial de presentación de su Correo Literario, Reyes introdujo algunas notas sobre las sociabilidades, (Agulhon, 209, p. 31$)^{10}$ relativas al mundo de la literatura y los intelectuales. Sugería Reyes que el periódico literario progresivamente iba sustituyendo "a lo que en otros tiempos era el salón, o a lo que era también el trato epistolar; a lo que más tarde ha sido el café. La tertulia, la

\footnotetext{
${ }^{9}$ Monterrey. Correo literario de Alfonso Reyes, tuvo 15 números que, en realidad fueron 14 ya que el número dos tuvo que ser diagramado nuevamente por Reyes dadas las imperfecciones tipográficas con que había salido la versión inicial de este número. Reyes fue su creador, editor, director y distribuidor. Casi todos ellos fueron editados en Brasil, cuando Reyes era el embajador mexicano en este país. El número uno salió en Río de Janeiro, en junio de 1930 y el 14 y último en Buenos Aires, 7 años y un mes después, en julio de 1937. La periodicidad era muy irregular: bimensual, trimestral, cuatrimestral semestral y hasta anual.

${ }^{10}$ Agulhon, p. 31 afirma que no parece conocerse un empleo de este término anterior al siglo XVIII. De acuerdo con este autor, el Dictionnaire de l'Académie Française, "cuyo retraso respecto del uso es bien conocido, admite el término en su edición del año V". También señala el historiador francés que el primer autor que habría fijado la sociabilidad como categoría filosófica sería el naturalista metafísico ginebrino Charles Bonnet, 1720-1793.
} 
conversación literaria, van pasando de la viva voz a la palabra estampada". ${ }^{11}$ Tanto la tertulia literaria como el café hacen parte de una serie de espacios de sociabilidad mediante los cuales el campo literario fue tomando autonomía. En tal proceso los periódicos, las revistas literarias y, en general las revistas, al igual que sus comités editoriales, como los editores, fueron muy importantes para ir definiendo el campo literario (Bourdieu, 2005, p. 87). Es muy interesante lo que Reyes plantea a propósito de que la conversación literaria fue pasando, "de la viva voz a la palabra estampada". Evidentemente este tránsito es muy anterior al surgimiento de Monterrey. Pero como hipótesis se puede plantear que el impulso que los periódicos literarios y las revistas literarias tuvieron durante las primeras décadas del siglo $\mathrm{XX}$, bajo el influjo del modernismo y el vanguardismo, fue un momento de mucha importancia para acabar de estructurar el cambio señalado por Reyes. Es muy interesante ver cómo uno de los intelectuales centrales en el mundo latino-europeo e hispano-americano de la primera mitad del siglo XX, percibía el cambio progresivo de lo que durante el siglo XIX había constituido la "república de las letras", hacia un campo intelectual y literario de las primeras décadas del siglo XX en donde entre otros elementos, como lo han señalado diferentes autores, habrá que tener en cuenta la diferenciación que el intelectual del periodo en estudio establece con el "pensador" del siglo XIX. En esta senda diferenciadora (Zermeño, 2010, p. 388) ha resaltado las figuras de José Enrique Rodó y de Rubén Darío. "Estas dos personalidades hacen del retiro del mundo y del cultivo de la forma y del estilo un fin en sí mismo; ponen en juego en ese sentido, el fondo de la forma del intelectual de nuevo cuño. Realizado este doble movimiento de aislamiento y cultivo de la forma, protegidos por la sombra de los ateneos y parnasos, se procederá luego a cumplir la función de iluminación y servir de guías espirituales para hacer que prevalezcan en la sociedad, antes que nada, la inteligencia, "la idea pura". Generacionalmente un poco posterior a Rodó y a Rubén Darío, Alfonso Reyes le dio continuidad al nuevo perfil y función social del intelectual.

\section{Algunas notas finales}

En el contexto de la primera mitad del siglo $X X$ y particularmente en sus décadas centrales, Alfonso Reyes y su trayectoria intelectual, diplomática y como escritor, logran trazar una órbita cultural en la cual se inscriben muchos otros intelectuales y escritores. En este sentido habrá que subrayar nuevamente cómo muchas de las facetas de la labor intelectual del mexicano, embonan en muchos de los presupuestos que configuran un nuevo campo intelectual. Reyes condensa en buena medida algunos de los aspectos que definen al intelectual de "nuevo cuño"., al intelectual del siglo XX. Su carácter de escritor profesional, su red intelectual, su trayectoria académica, sus proyectos culturales, su calidad de intelectual de la Revolución mexicana y su relación con empresas culturales (revistas, libros y periódicos) entre otros aspectos, son prueba de una labor que

\footnotetext{
${ }^{11}$ Monterrey, núm. 1, junio de 1930, p. 2.
} 
incidió directamente en la transformación del campo intelectual latinoamericano durante el periodo estudiado en esta investigación.

Este nuevo tipo de "sabio" conlleva en sí mismo ciertas características que progresivamente y durante la primera mitad del siglo XX latinoamericano rompe con el "sabio" de la "república de las letras" del siglo XIX. Una de esas características es que este nuevo intelectual se asume como escritor profesional y que se crea un espacio cultural en el que los periódicos, las revistas, las instancias de consagración, los comités editoriales, y las organizaciones literarias, entre otros aspectos, redundan en la emergencia de una nueva esfera de opinión pública en donde el nuevos perfil y circunstancias de los intelectuales los convierte en la conciencia moral de la sociedad.

\section{REFERENCIAS BIBLIOGRÁFICAS}

Agulhon, Maurice. (2009). El círculo burgués. La sociabilidad en Francia, 18101848. Argentina: Siglo XXI Editores, ( $1^{\circ}$ ed. 1977$)$.

Aillón, Esther. (2009). "La política cultural de Francia en la génesis y difusión del concepto L'amérique Latine, 1860-1930". En Granados, Aimer \& Marichal, Carlos (compiladores), Construcción de las identidades latinoamericanas. Ensayos de historia intelectual. Siglos XIX y XX. México: El Colegio de México, primera reimpresión, pp.71-105.

Altamirano, Carlos. (1997). "La fundación de la literatura argentina". En Altamirano, Carlos \& Sarlo, Beatriz, Ensayos argentinos. De Sarmiento a la Vanguardia. Argentina: Ariel, pp. 201-209.

Altamirano, Carlos \& Sarlo, Beatriz. (1997). "La Argentina del Centenario: campo intelectual, vida literaria y temas ideológicos". En, Ensayos argentinos. De Sarmiento a la Vanguardia. Argentina: Ariel, pp. 161-199.

Altamirano, Carlos (director). (2010). Historia de los intelectuales en América Latina II. Los avatares de la "ciudad letrada" en el siglo XX. Buenos Aires: Katz Editores.

Aponte, Bárbara Ann Bockus. (1972). Alfonso Reyes and Spain. Austin: University of Texas Press.

Bourdieu, Pierre. (2005). Las reglas del arte. Génesis y estructura del campo literario. Barcelona: Anagrama.

Castañón, Adolfo. (2008). "Alfonso Reyes: de la diplomacia considerada como una de las bellas artes". En Ortega, Julio \& del Palacio, Celia (coordinadores), México trasatlántico. México: Fondo de Cultura Económica / Universidad de Guadalajara, pp. 195-208. 
Charle, Christophe. (2009). El nacimiento de los "intelectuales". Buenos Aires: Nueva Visión.

Díaz Arciniega, Víctor. (2001). Prólogo: "El organizador de la esperanza". En Alfonso Reyes. Misión Diplomática. México: Secretaría de Relaciones Exteriores / Fondo de Cultura Económica, pp. 9-116.

Enríquez Perea, Alberto. (2009). Alfonso Reyes en los albores del Estado Nuevo brasileño (1930-1936). México: El Colegio Nacional.

El colegio de México. (2000). Diplomacia y Revolución. Homenaje a Berta Ulloa. México: El Colegio de México.

Ellison, Fred P. (2000). Alfonso Reyes y el Brasil. Un mexicano entre los cariocas. México: CONACULTA.

Garciadiego, Javier. (1988). "Alfonso Reyes. Cosmopolitismo diplomático y universalismo literario". En Secretaría de Relaciones Exteriores, Escritores en la diplomacia mexicana. México: Secretaría de Relaciones Exteriores.

(2000). "Alfonso Reyes, embajador en Argentina". En El Colegio de México, Diplomacia y Revolución. Homenaje a Berta Ulloa". México: El Colegio de México, pp. 97-121.

(2006). "Alfonso Reyes exiliado en España". En Cultura y política en el México posrevolucionario. México: INEHRM, pp. 217-227.

México: INEHRM.

(2006). Cultura y política en el México posrevolucionario. (2009). Alfonso Reyes. Breve biografía. México: Planeta.

Gramsci, Antonio. (2009). Los intelectuales y la organización de la cultura. Buenos Aires: Nueva Visión.

Granados, Aimer. "Introducción" a Las revistas en la historia intelectual de América Latina. Redes, política, sociedad y cultura. México: Universidad Autónoma Metropolitana-Cuajimalpa / Editorial Juan Pablos, en prensa.

. "Monterrey. Correo Literario de Alfonso Reyes. Campo literario y red intelectual en América Latina". México: Universidad Autónoma Metropolitana-Cuajimalpa / Editorial Juan Pablos, en prensa.

(2008). "La literatura mexicana durante la Revolución: entre el nacionalismo y el cosmopolitismo". En Illades, Carlos y Leidenberger, Georg (coordinadores). México: CONACULTA/UAM-Cuajimalpa, pp. 157-185. 
Granados, Aimer \& Carlos Marichal (compiladores). (2009). Construcción de las identidades latinoamericanas. Ensayos de historia intelectual. Siglos XIX y XX. México: El Colegio de México, primera reimpresión.

Hernández Luna, Juan. (1984). Conferencias del Ateneo de la juventud. México: Universidad Nacional Autónoma de México.

Krauze, Enrique. (1996). Caudillos culturales en la Revolución mexicana. México: Siglo XXI Editores, octava edición.

Losada, Leandro. (2009). Historia de las élites en la Argentina. Desde la Conquista hasta el surgimiento del Peronismo. Buenos Aires: Sudamericana.

Martínez, José Luis. (1989). "Las memorias de Alfonso Reyes", Nueva Revista de Filología Hispánica, XXXVII, núm. 2, pp. 487-504.

Myers, Jorge. (2010). "El intelectual-diplomático: Alfonso Reyes sustantivo". En, Carlos Altamirano (director), Historia de los intelectuales en América Latina II. Los avatares de la "ciudad letrada" en el siglo XX. Buenos Aires: Katz Editores, pp. 82-97.

Ortega, Julio \& del Palacio, Celia (coordinadores). (2008). México trasatlántico. México: Fondo de Cultura Económica / Universidad de Guadalajara.

Patout, Paulette. (1990). Alfonso Reyes y Francia. México: El Colegio de México / Gobierno del Estado de Nuevo León.

Perea, Héctor. (1997). España en la obra de Alfonso Reyes. México: Fondo de Cultura Económica.

Quintanilla, Susana. (2008). "Nosotros". La juventud del Ateneo de México. De Pedro Henríquez Ureña y Alfonso Reyes a José Vasconcelos y Martín Luis Guzmán. México: Tusquets editores.

Reyes, Alfonso. Monterrey. Correo Literario de Alfonso Reyes. Capilla Alfonsina, Ciudad de México.

Guanajuato.

(1969). Diario, 1911-1930. Guanajuato: Universidad de (1986). Correspondencia: 1907-1914. Alfonso Reyes y Pedro Henríquez Ureña. México: Fondo de Cultura Económica.

(2001). Alfonso Reyes. Misión Diplomática, Compilación de Víctor Díaz Arciniega. México: Secretaría de Relaciones Exteriores / Fondo de Cultura Económica, dos tomos. 
Secretaría de Relaciones Exteriores. (1988, 2000 y 2002). Escritores en la diplomacia mexicana, tres volúmenes. México: Secretaría de Relaciones Exteriores.

Winock, Michel. (2010). El siglo de los intelectuales. España: Edhasa.

Yankelevich, Pablo. (1994). La diplomacia imaginaria. Argentina y la Revolución Mexicana, 1910-1916. México: Secretaría de Relaciones Exteriores.

(1997). Miradas australes. Propaganda, cabildeo y proyección de la Revolución Mexicana en el Río de la Plata, 1910-1930. México: Instituto Nacional de Estudios Históricos de la Revolución Mexicana / Secretaría de Relaciones Exteriores.

(2003). La revolución mexicana en América Latina. Intereses políticos e itinerarios intelectuales. México: Instituto Mora.

Zermeño, Guillermo. (2003). "El concepto intelectual en Hispanoamérica: Génesis y evolución”. En Historia Contemporánea, 27, pp. 777-798.

- (2010). "La invención del intelectual en México". En, Roberto Blancarte (coordinador), Cultura e identidades de la colección Los grandes problemas de México. México: El Colegio de México, pp. 379-403.

Recibido: Octubre 27 de 2011

Aprobado: Mayo 7 de 2012 